\title{
Vitamin D receptors in the rheumatoid lesion: expression by chondrocytes, macrophages, and synoviocytes
}

\author{
Lynne C Tetlow, Susan J Smith, E Barbara Mawer, David E Woolley
}

\begin{abstract}
Objectives-The active form of vitamin $D_{3}, 1 \alpha, 25$ dihydroxyvitamin $D_{3}\left(1,25 D_{3}\right)$, through its interaction with vitamin D receptors (VDR), is reported to effect a variety of anabolic and catabolic events, especially in bone and cartilage tissues. As cartilage degradation and tissue remodelling are characteristic features of the rheumatoid lesion, the distribution and expression of VDR at sites of cartilage erosion was examined.
\end{abstract}

Methods-Immunolocalisation techniques using a rat monoclonal antibody to VDR and an alkaline phosphatase conjugated avidin/biotin detection system were used to examine VDR in 18 specimens of cartilage-pannus junction, 10 specimens of rheumatoid synovium or cartilage tissue, and four primary cultures of adherent rheumatoid synovial cells (RSC). For comparison, VDR expression was examined in 10 specimens of normal, healthy age matched articular cartilage.

Results-VDR was demonstrated in 15 of 18 cartilage-pannus junctions either at the interface ( 8 of 18$)$, within the pannus tissue (12 of 18), and by chondrocytes often close to the erosive lesion (10 of 18). All the rheumatoid synovial tissue and 5 of 10 cartilage specimens showed cells with positive staining, but the extent of this was variable. Negligible VDR staining was observed for normal cartilage. Primary cultures of RSC also showed variability in both the numbers and proportions of macrophages or synovial fibroblasts stained for VDR (range 10-50\%), this being more common in cultures with a high proportion of macrophages.

Conclusions-VDR expression has been demonstrated by most specimens of cartilage-pannus junction; was associated with various cell types, including chondrocytes, but not exclusively with $\mathrm{CD}^{+} 8^{+}$macrophages. The focal nature of VDR expression within the rheumatoid lesion suggests a contributory role for $1 \alpha, 25 \mathrm{D}_{3}$ in the pathophysiological processes of rheumatoid arthritis.

(Ann Rheum Dis 1999;58:118-121)

Medicine, Manchester

Royal Infirmary,

Oxford Road,

Manchester, M13 9WL

Correspondence to:

Dr D E Woolley.

Accepted for publication

15 September 1998
The biologically active metabolite of vitam $\mathrm{D}, 1 \alpha, 25$ dihydroxyvitamin $\mathrm{D}_{3}\left(1,25 \mathrm{D}_{3}\right)$, has a recognised role in a variety of bone and mineral disorders such as Rickets and osteoporosis, has a pivotal role in calcium and phosphorous metabolism, and has been shown to have other biological roles such as the regulation of cell proliferation, differentiation and immune function. ${ }^{1} 1,25 \mathrm{D}_{3}$ functions by binding to specific intracellular vitamin D receptors (VDR) that are expressed by a variety of cell types. These include monocytes, fibroblasts, activated lymphocytes, and various myeloid cells. ${ }^{12}$ Recent studies have examined the roles of $1,25 \mathrm{D}_{3}$ and VDR expression in chondrocyte cultures and their contribution to the behaviour of different zones of growth plate cartilage. ${ }^{34}$ Such studies have shown that vitamin D metabolites are capable of regulating the transcription of a large number of genes relating to both anabolic and catabolic events of chondrocytes in culture. ${ }^{135}$ Their effects on chondrocyte phenotype are shown to be dependent upon the cartilage source and the differentiated state. ${ }^{67}$ For example, vitamin D metabolites are reported to modulate chondrocyte functions such as proteoglycan and collagen synthesis, ${ }^{57}$ and to regulate specific matrix metalloproteinase expression by chondrocytes $^{89}$ as well as human mononuclear phagocytes. ${ }^{10}$

Human blood derived macrophages are reported to express mRNA for $\mathrm{VDR}^{11}$ and functional VDR have been detected in pulmonary alveolar macrophages, ${ }^{12}$ but to date no reports of VDR at sites of cartilage erosion in rheumatoid arthritis (RA) have been published. Here we demonstrate, by immunolocalisation, that different types of cell in the rheumatoid lesion express VDR, suggesting the possibility that vitamin D metabolites could be implicated in the pathophysiological processes associated with rheumatoid disease.

\section{Methods}

Samples of rheumatoid synovial tissue $(n=10)$, cartilage tissue $(n=10)$, and cartilage-pannus junction $(n=18)$ were obtained from arthroplasty specimens from patients with classic late stage RA. Normal articular cartilage samples $(n=10)$ were obtained from lower limb amputations. Tissue samples were fixed in Carnoy's fixative at $20^{\circ} \mathrm{C}$ for $1-2$ hours, embedded in paraffin wax and $5 \mu \mathrm{m}$ sections cut. Tissue sections were dewaxed, rehydrated, and examined for the presence of VDR; in some cases consecutive sections were also examined for the presence of macrophages. In addition rheumatoid synovial tissue $(n=4)$ was enzymically digested as previously described, ${ }^{13}$ and the resulting adherent cell cultures were grown on glass coverslips in Dulbecco's modified 
Eagle's medium with $10 \%$ fetal calf serum supplement for 24 hours before fixation in $70 \%$ ethanol and subsequent immunostaining. ${ }^{13}$

IMMUNOLOCALISATION OF VDR

Tissue sections were pretreated with $2 \mathrm{~N} \mathrm{HCl}$ at $37^{\circ} \mathrm{C}$ for 30 minutes, this being the antigen retrieval procedure recommended by the supplier. Non-immune rabbit serum at $10 \%(\mathrm{v} / \mathrm{v})$ in TRIS buffered saline (TBS) was applied to the sections for 20 minutes at $20^{\circ} \mathrm{C}$ before incubation with the primary antibody. Rat monoclonal antibody to chick VDR (known to cross react with human VDR), (Biogenex, San Ramon, USA) was applied to the sections for two hours at $20^{\circ} \mathrm{C}$ after dilution 1:40 in TBS. After $3 \times 10$ minute washing in TBS, biotinylated rabbit antirat IgG (DAKO, Glostrup, Denmark) diluted 1:200 in TBS was applied to the sections for 45 minutes at $20^{\circ} \mathrm{C}$. After further washing in TBS, alkaline phosphatase conjugated ABC (Avidin-Biotin system, DAKO) was applied to the sections for 45 minutes at $20^{\circ} \mathrm{C}$, diluted as instructed by the supplier. After further washes in TBS the alkaline phosphatase was developed using New Fuchsin substrate to give a red colour. Adherent primary cell cultures were rehydrated in TBS immediately after fixation and immunostained for VDR as described above.

IMMUNOLOCALISATION OF MACROPHAGES

Consecutive tissue sections to those immunostained for the VDR were immunostained for macrophages using mouse monoclonal antibody (CD68/KP1, DAKO) diluted $1: 100$ in TBS. Biotinylated rabbit antimouse IgG secondary antibody (diluted 1:300, DAKO) was used with the procedure as described above.

\section{CONTROL TISSUE SECTIONS}

Controls consisted of substituting the primary antibodies with non-immune rat or mouse IgG at similar concentrations and proceeding as described above. All consistently gave negative results.

DUAL IMMUNOLOCALISATION OF VDR AND MACROPHAGES IN PRIMARY CELL CULTURES Cells were rehydrated in TBS and pretreated with $10 \%(\mathrm{v} / \mathrm{v})$ goat serum and $10 \%(\mathrm{v} / \mathrm{v})$ rabbit serum in TBS for 10 minutes at $20^{\circ} \mathrm{C}$. Rat monoclonal antibody to VDR and mouse monoclonal antibody to macrophages (CD68/

Table 1 Frequency of VDR positive cells in rheumatoid tissues

\begin{tabular}{|c|c|c|c|c|c|}
\hline \multirow[b]{2}{*}{$V D R^{+}$specimens/total } & \multicolumn{5}{|c|}{ Assessment of positive staining } \\
\hline & ++++ & +++ & ++ & + & - \\
\hline \multicolumn{6}{|l|}{1 Rheumatoid synovium ${ }^{\star}(n=10)$} \\
\hline $\begin{array}{l}10 / 10 \\
2 \text { "Rheumatoid" cartilage }(n=10)\end{array}$ & 1 & 4 & 3 & 2 & 0 \\
\hline $\begin{array}{l}2 \text { "Rheumatoid" cartilage }(\mathrm{n}=10) \\
5 / 10\end{array}$ & 0 & 0 & 0 & 5 & 5 \\
\hline \multicolumn{6}{|l|}{3 CPJs ( $n=18)$} \\
\hline chondrocytes $10 / 18$ & 0 & 0 & 3 & 7 & 8 \\
\hline pannus $12 / 18$ & 0 & 0 & 3 & 9 & 6 \\
\hline & 0 & 0 & 2 & 6 & 10 \\
\hline \multicolumn{6}{|l|}{4 Normal cartilage $(n=10)$} \\
\hline $1 / 10$ & 0 & 0 & 0 & 1 & 9 \\
\hline
\end{tabular}

,,++++++ , and ++++ represent gradings of $<5,5-10,10-20$ and up to $60 \%$ of total cells, respectively, as determined by two independent assessors; - , no cells stained for VDR. ${ }^{\star}$ Synovial tissue remote from cartilage interface.
KP1) were diluted in TBS (1:40 and 1:100, respectively) and applied to the coverslips for two hours at $20^{\circ} \mathrm{C}$. After washing three times in TBS, biotinylated rabbit antirat IgG (DAKO) diluted 1:200 and fluoroisothiocyanate (FITC) conjugated goat antimouse IgG (DAKO) diluted 1:20 were applied for one hour at $20^{\circ} \mathrm{C}$. Both secondary antibodies were preabsorbed to eliminate cross species reactivity. After washing three times, alkaline phosphatase conjugated $\mathrm{ABC}(\mathrm{DAKO})$ was applied to the sections for 45 minutes at $20^{\circ} \mathrm{C}$ and subsequently developed using Fast Red, which fluoresces under conventional filter sets for rhodamine or Texas red. Coverslips were washed and mounted in Immumount (Shandon). Fluorescence was viewed with filter sets for FITC or FR.

All tissue sections were lightly counterstained in either Harris's haematoxylin or acidified Toluidine blue, dehydrated, cleared and subsequently mounted in Histomount (Mensura Technology, Wigan, UK). Tissue sections and cell cultures were examined and photographed using a Zeiss Photomicroscope III and Ektachrome 160 tungsten film.

\section{Results}

VDR EXPRESSION AT CARTILAGE-PANNUS

JUNCTIONS (CPJS)

Most of the 18 specimens of CPJ examined for VDR expression showed positively stained cells (table 1). Twelve specimens showed significant staining of synoviocytes within the pannus tissue, 10 demonstrated staining of chondrocytes within the cartilage matrix, and eight specimens showed VDR expression by cells at the cartilage-pannus interface (fig $1 \mathrm{a}$ and $\mathrm{b}$ ). In all cases the cellular staining was restricted to a variable proportion of the total cells within each tissue. This was particularly evident with the cartilage where chondrocytes located close to the cartilage:pannus interface were more likely to demonstrate VDR staining. Indeed, 8 of the $18 \mathrm{CPJ}$ specimens showed prominent staining of cells in immediate contact with the cartilage matrix (fig 1b); such observations were restricted to microfoci, and never extended along the whole length of any CPJ specimen. By contrast, nearly all of the 10 specimens of normal articular cartilage showed no evidence of VDR expression (fig 1c; table 1).

VDR EXPRESSION IN RHEUMATOID SYNOVIAL TISSUE OR CARTILAGE

All of the 10 synovial specimens examined contained some cells stained for VDR, but the extent of this staining was variable, ranging from very few to up to $50 \%$ of total cells in one specimen (table 1). Immunostaining for macrophages using the CD68 marker showed that these cells were often associated with VDR expression, as judged by consecutive sections stained for both antigens. However, VDR expression within synovial tissue was not exclusive to macrophages; a minor proportion of other cells negative for CD68 such as fibroblastic synoviocytes, lymphocytic infiltra- 
tions containing a high proportion of B cells and endothelial cells were also positively stained for VDR (fig 1e and f).
Cartilage specimens from RA joints also showed a proportion of chondrocytes immunostained for VDR (5 of 10), especially in the
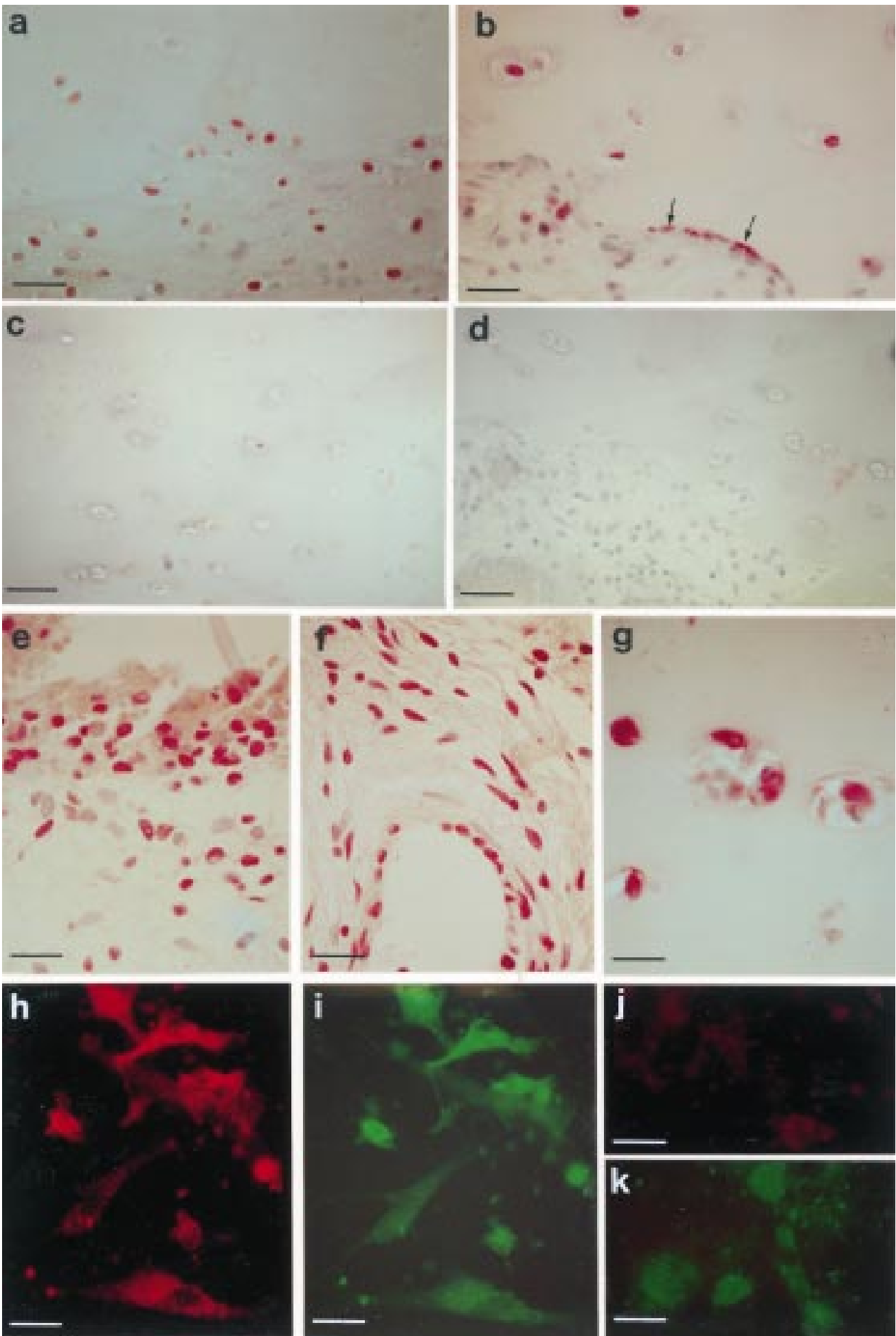

Figure 1 Immunolocalisation of VDR in rheumatoid tissues, normal cartilage, and primary synovial cell cultures. (a) VDR production (red stain) by a proportion of synovial cells close to the CPF. (b) VDR expression by cells at the cartilage interface (arrows) and by some chondrocytes at the CPF. (c) Note absence of VDR expression by chondrocytes of normal articular cartilage. (d) Negative control: adjacent tissue section to (b) in which primary rat antibody was substituted with normal rat IgG. (e) VDR expression by cells of the synovial lining layer and a proportion of sub-lining synoviocytes. $(f)$ $V D R$ production by endothelial cells and a proportion of the rheumatoid synoviocytes. $(g)$ VDR expression by chondrocytes close to the CPF. (h) Primary culture of RSC stained for VDR with Fast Red (i) same field as (h) stained with macrophage marker, CD68 (green). (j) and (k) Negative controls for the staining procedures used in (h) and (i) respectively. Note that all the VDR staining is intracellular; and that all micrographs also illustrate negatively stained cells.

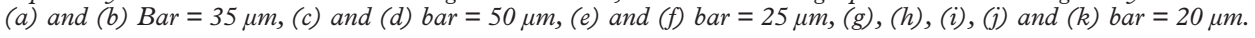


superficial rather than deeper zones of the cartilage (fig 1g, table 1).

VDR EXPRESSION BY PRIMARY CULTURES OF RSC Adherent RSC are usually restricted to cells of the fibroblastic and macrophagic morphologies, the proportions of these cell types varying both with individual specimens and with time in culture. ${ }^{13}$ Each of four cultures examined showed some positive staining for VDR, but this ranged from approximately $10 \%$ in one culture to approximately $60 \%$ in another. CD68 staining of each RSC culture indicated that the VDR was more prominent in those cultures containing more macrophages, but VDR was not exclusive to these cells (fig $1 \mathrm{~h}$ and $\mathrm{i}$ )

\section{Discussion}

$1,25 \mathrm{D}_{3}$ has a recognised role in a variety of bone and mineral disorders, and has been shown to modulate cell proliferation, differentiation, and immune functions. ${ }^{1}$ Of special interest were reports that $1,25 \mathrm{D}_{3}$ caused an increase in matrix metalloproteinase (MMP) production by chondrocytes in vitro, ${ }^{89}$ and that it regulates the levels of interleukin 1 in growth plate cartilage. ${ }^{3}$ Moreover, $1,25 \mathrm{D}_{3}$ has been shown to modulate specific MMP production by macrophages, especially MMP-1 and MMP-9. ${ }^{10}$

This paper provides evidence for the in vivo expression of VDR by various cells of the rheumatoid lesion, including macrophages, chondrocytes, and synoviocytes. By contrast, normal articular cartilage was devoid of VDR expression with negligible staining being observed in only 1 of 10 specimens. Such observations suggest that VDR expression is significantly upregulated in RA tissues. Our earlier studies have used dual immunolocalisation techniques to demonstrate the codistributions of the proinflammatory cytokines IL1 $\beta, T N F \alpha$, together with MMP-1 and MMP-3 within microfocal sites of the rheumatoid lesion. ${ }^{14}$ At present it is not known whether VDR expression is present within such tissue sites. However, the recent reports that macrophages from synovial fluids can synthesise $1,25 \mathrm{D}_{3}{ }^{1516}$ and the increased concentrations of vitamin $\mathrm{D}$ metabolites reported in human arthritic synovial fluids, ${ }^{17}$ lend support to the concept that VDR and $1,25 \mathrm{D}_{3}$ could well participate in the pathophysiological processes of the rheumatoid lesion.
This work was supported by a grant (no W0541) from the Arthritis Research Campaign. We thank consultant orthopaedic surgeons T Dunningham (Tameside Hospital, Manchester) and M Morris (Devonshire Royal Hospital, Buxton) for the supply of rheumatoid tissues, and Professor A Freemont (University of Manchester) for help with the supply of normal cartilage.

1 Walters MR. Newly identified actions of the vitamin D endocrine system. Endocr Rev 1992;13:719-64.

2 Binderup L. Immunological properties of vitamin D analogues and metabolites. Biochem Pharmacol 1992;43: analogues

3 Dean DD, Schwartz Z, Muniz OE, Arsenis CH, Boyan BD, Howell DS. Interleukin- $1 \alpha$ and $\beta$ in growth plate cartilage are regulated by vitamin D metabolites. J Bone Miner Res 1997;12:1560-9.

4 Boyan BD, Schwartz Z, Carnes DL, Ramirez V. The effects of vitamin $\mathrm{D}$ metabolites on the plasma and matrix vesicle membranes of growth and resting cartilage cells in vitro. membranes of growth and resting

5 Goldring MB. Degradation of articular cartilage in culture: Regulatory factors. In: Woessner JF, Howell DS, eds. Foint cartilage degradation - basic and clinical aspects. New York: Marcel Dekker, 1993:281-345.

6 Gerstenfeld LC, Kelly CM, von Deck M, Lian JB. Effect of 1,25-dihydroxyvitamin $\mathrm{D}_{3}$ on induction of chondrocyte maturation in culture: extracellular matrix gene expression and morphology. Endocrinology 1990;126:1599-609.

7 Boyan BD, Posner GH, Greising DM, White MC, Sylvia VL, Dean DD, et al. Hybrid structural analogues of $1,25(\mathrm{OH})_{2} \mathrm{D}_{3}$ regulate chondrocyte proliferation and proteoglycan production as well as protein kinase $\mathrm{C}$ through a nongenomic pathway. J Cell Biochem 1997;66:457-70.

8 Grumbles RM, Shao L, Jeffrey JJ, Howell DS. Regulation of rat interstitial collagenase gene expression in growth cartilage and chondrocytes by vitamin $\mathrm{D}_{3}$, interleukin $1 \beta$ and okadaic acid. J Cell Biochem 1996;63:395-409.

9 Dean DD, Boyan BD, Muniz OE, Howell DS, Schwartz Z. Vitamin $\mathrm{D}$ metabolites regulate matrix vesicle metalloproteinase in a cell maturation-dependent manner. Calcif Tissue Int 1996;59:109-16.

10 Lacraz S, Dayer J-M, Nicod L, Welgus HG. 1,25 dihydroxyvitamin $\mathrm{D}_{3}$ dissociates production of interstitial collagenase and $92-\mathrm{kD}$ a gelatinase in human mononuclear phagocytes. J Biol Chem 1994;269:6485-90.

11 Kizaki M, Norman AW, Bishop JE, Lin CW, Karmaker A, Koeffler HP. 1,25 dihydroxyvitamin $\mathrm{D}_{3}$ receptor RNA: Expresion in haematopoietic cells. Blood 1991;77:123847.

12 Bishop JE, Reichel H, Koeffler HP, Norman AW. 1,25(OH $)_{2}$ $\mathrm{D}_{3}$ receptor in pulmonary alveolar macrophages. In: Norman AW, Schaefer K, Grogoleit HG, Herrath DV, eds. Vitamin D: chemical, biochemical and clinical update. New York: Walter de Gruyter, 1985:127-8.

13 Tetlow LC, Lees M, Ogata Y, Nagase H, Woolley DE. Differential expression of gelatinase B (MMP-9) and stromelysin 1 (MMP-3) by rheumatoid synovial cells in vitro and in vivo. Rheumatol Int 1993;13:53-9.

14 Tetlow LC, Woolley DE. Mast cells, cytokines and metalloproteinases at the rheumatoid lesion: dual immunolocalisation studies. Ann Rheum Dis 1995;54:896-903.

15 Hayes ME, Denton J, Freemont AJ, Mawer EB. Synthesis of the active metabolite of vitamin $\mathrm{D}, 1,25(\mathrm{OH})_{2} \mathrm{D}_{3}$ by synovial fluid macrophages in arthritic diseases. Ann Rheum Dis $1989 ; 48: 723-9$.

16 Mawer EB, Hayes ME, Still PE, Davies M, Lumb GA, Palit $\mathrm{J}$, et al. Evidence for non-renal synthesis of 1,25 dihydroxyvitamin $\mathrm{D}$ in patients with inflammatory arthritis. J Bone Miner Res 1991;6:733-9.

17 Inaba M, Yukioka K, Furumitsu Y, Murano M, Goto H, Nishizawa Y, et al. Positive correlation between levels of IL-1 or IL-2 and $1,25(\mathrm{OH})_{2} \mathrm{D} / 25 \mathrm{OHD}$ ratio in synovial fluid of patients with rheumatoid arthritis. Life Sci 1997;61:977-98. 